\title{
Respon Pertumbuhan dan Hasil Kedelai terhadap Pupuk Hayati di Lahan Sawah Di Kabupaten Pandeglang, Banten
}

\section{Response of Growth and Soybean Results using Biological Fertilizer in Rice Field in Pandeglang Regency, Banten}

\author{
Yati Astuti $^{1^{*}}$, dan Resmayeti Purba ${ }^{1}$ \\ ${ }^{1}$ Balai PengkajianTeknologi Pertanian Banten \\ Jl.Raya Ciptayasa Km 01 Ciruas, Serang, Banten, Indonesia, 42182 \\ E-mail: yutia_84@yahoo.com
}

Diterima 23 Desember 2016/Disetujui 26 Maret 2017

\begin{abstract}
The purpose of this study is to determine the effectiveness of the use of biofertilizer on growth and yield of soybean.The experiment was conducted in the paddy field Mekarsari village, Panimbang Subdistrict, Pandeglang District, Banten Province from Agustus 2016 to Oktober 2016. The experimental was laid out in randomized block design with single factorwith five treatments and six replications. The treatments were (A). Without fertilization (control); (B). Recommended fertilizer(25 $\mathrm{kgha}^{-1}$ of urea $+100 \mathrm{kgha}^{-1} \mathrm{SP}-36+100 \mathrm{kgha}^{-1} \mathrm{NPK}$ Phonska), (C) Agrimethbiofertilizer $200 \mathrm{gha}^{-1}+$ recommended fertilizer, (D) Agrimeth biofertilizer200gha ${ }^{-1}+$ Gliocompost biofertilizer20 $\mathrm{kgha}^{-1}+$ recommended fertilizer, (E) Gliocompost biofertilizer $20 \mathrm{kgha}^{-1}+$ recommended fertilizer. The observed parameters were plant height, leaves number, root length, number of root nodules, number of flower, number of filled pods, grain yield. Data were analyzed using ANOVA with advanced test using DMRT with $\alpha 5 \%$. showed that the use of Agrimeth $200 \mathrm{gha}^{-1}+$ Gliocompost $20 \mathrm{kgha}^{-1}+$ recommended fertilizer significantly affect plant growth, ie plant height, leaves number,number of root nodules, number of flower, number of filled pods and soybean yields. Agrimeth $200 \mathrm{gha}^{-1}+$ Gliocompost $20 \mathrm{kgha}^{-1}+$ recommended fertilizer increase yield of soybean from 0.89tha-1 to 2.01 tha $^{-1}$.
\end{abstract}

Keywords: Agrimeth, Gliocompost, soybean

\section{ABSTRAK}

Penelitian bertujuan untuk mengetahui pemanfaatan pupuk hayati terhadap pertumbuhan dan hasil kedelai. Penelitian dilaksanakan di lahan sawah desa Mekarsari Kec. Panimbang, Kabupaten Pandeglang, Banten dari bulan Agutus 2016 hinggaOktober 2016. Rancangan percobaan yang digunakan adalah acak kelompok factor tunggaldengan lima perlakuan dan enam ulangan. Perlakuannya adalah (A). Tanpa pemupukan (kontrol); (B). Pupuk rekomendasi: $25 \mathrm{kgha}^{-1}$ Urea $100 \mathrm{kgha}^{-1}$ $S P-36+100$ kgha $^{-1}$ NPK Phonska, $(C)$ pupuk hayati Agrimeth 200 gramha $^{-1}+$ pupuk rekomendasi $(D)$. pupuk hayati Agrimeth 200 gramha $^{-1}+$ Gliocompost $20 \mathrm{kgha}^{-1}+$ pupuk rekomendasi (E) pupuk hayati Gliocompost $20 \mathrm{kgha}^{-1}+$ pupuk rekomendasi. Parameter yang diamatia dalah tinggi tanaman, jumlah daun, panjang akar, jumlah bintil akar, jumlahbunga, jumlah polong isi, hasil biji kedelai.Data hasil pengamatan dianalisis dengan menggunakan Analysis of Varians (ANOVA). Data yang berbeda nyata diuji lanjut menggunakan uji Duncan Multiple Range Test (DMRT) pada taraf nyata (a) 0.5\%. Hasil penelitian menunjukkan bahwa pupuk hayati Agrimeth $200 \mathrm{gha}^{-1}+$ pupuk hayati Gliocompost $20 \mathrm{kgha}^{-1}+$ pupuk rekomendasi berpengaruh nyata terhadap pertumbuhan tanaman, yaitu tinggi tanaman,jumlah daun, jumlah bintil akar, jumlah bunga, jumlah polong isi dan hasil kedelai. Pupuk hayati Agrimeth $200 \mathrm{gha}^{-1}+$ pupuk Gliocompost $20 \mathrm{~kg} \mathrm{ha}^{-1}+$ pupuk rekomendasi meningkatkan hasil kedelai dari 0,89 tha $^{-1}$ menjadi 2,01 tha' ${ }^{-1}$.

Kata Kunci: Agrimeth, Gliocompost, kedelai.

\section{PENDAHULUAN}

Budidaya kedelai di lahan sawah di petani menunjukkan bahwa tingkat produktivitas berkisar 0,8-1,2 tha ${ }^{-1}$, penggunaan pupuk Urea 25-50 $\mathrm{kgha}^{-1}$, SP-36 50-100 $\mathrm{kgha}^{-1}$ dan NPK Phonska 50-100 $\mathrm{kgha}^{-1}$, dan tanpa menggunakan bahan organik. Sedangkan produktivitas kedelai ditingkat penelitian saat ini berkisar $1,5-2,5$ tha $^{-1}$ dengan pemupukan rekomendasi umum: Urea 100-150 $\mathrm{kgha}^{-}$ ${ }^{1}$; Sp-36 50-100 $\mathrm{kgha}^{-1}$, KCl 50-100 $\mathrm{kgha}^{-1}$ dan bahan organik 1-2 tha ${ }^{-1}$. Kesenjangan hasil petani dengan hasil penelitian antara lain disebabkan tanah di lahan sawah kekurangan bahan organik.Kondisi ini menyebabkan struktur tanah tidak dapat mendukung perkembangan akar 
dalam penyerapan unsur hara dan unsur hara tidak tersedia bagi tanaman kedelai. Akibatnya, pemupukan yang dilakukan petani tidak efisien karena unsur hara dari pupuk NPK tidak diserap tanaman.Upaya memperbaki kualitas tanah dapat diberikan pupuk hayati sebagai pembenah tanah. Pupuk hayati memiliki keunggulan yaitu: meningkatkan keanekaragaman dan aktivitas populasi mikroba tanah, memperbaiki struktur tanah, sebagai sumber hara, meningkatkan hasil tanaman, meningkatkan serapan hara oleh tanaman (Saraswati 2000; Suhartatik dan Sismiyati 2000; Sasli 2013).Penggunaan pupuk hayati pada tanaman kedelai bermanfaat memperbaiki kualitas tanah dan meningkatkan kandungan bahan organik(Saraswati 2013; Harsono et al., 2012; Harsono et al., 2013). Pemanfaatan pembenah tanah pupuk hayati pada budidaya kedelai merupakan upaya memperbaiki struktur fisik dan bilogi tanah sehingga akar tanaman dapat menyerap unsur hara lebih baik, yang akhirnya berdampak kepada pertumbuhan tinggi tanaman, jumlah daun, panjang akar, jumlah polong isi dan hasil biji kedelai.Keefektifan pupuk hayati dalam meningkatkan hasil kedelai telah dilaporkan beberapa peneliti. Pupuk hayati Iletrisoy-2 dan Rhizogin dapat meningkatkan hasil dari 1,10 tha $^{-1}$ menjadi 1,94 tha $^{-1}$; penggunaan Ileytrisoy-2 + Santap 1,5 tha $^{-1}$ meningkatkan hasil kedelai dari 1,10 tha ${ }^{-1}$ menjadi 1,82 tha $^{-1}$ (Harsono et al., 2012; Harsono et al., 2013).

BalaiPenelitian Tanah (2015) melaporkan bahwa komposisi Agrimeth: (a) Azotobacter vinelandii (penambat $\mathrm{N} 2$, non simbiotik dan pelarut $\mathrm{P}$ tanah), (b). Bacillus cereus (pelarut $\mathrm{P}$ tanah, penghasil senyawa anti patogen), (c). Bradyrhizobium sp dan Rhizobium sp (penambat $\mathrm{N} 2$ simbiotik), (d). Methlyobactterium sp (penghasil fitohormon). Selanjutnya Balai Penelitian Tanaman Hias (2015) melaporkan bahwa komposisi Gliocompost adalah Azospirillium sp., yang mempunyai keunggulan sebagai penyedia pupuk $\mathrm{N}$ dan Psecara alamiah, pembenah tanah, memperbaiki kualitas tanah dan membantu penyerapan unsur hara serta dan menjaga kesehatan tanaman. Berdasarkan keunggulan pupuk hayati tersebut maka dilakukan penelitian untuk mengetahui efektivitas pemanfaatan Agrimeth dan Gliocompost terhadap pertumbuhan dan hasil kedelai di lahan sawah, Kabupaten Pandeglang, Banten.

\section{BAHAN DAN METODE}

Penelitiandilaksanakanpadabulan Agustus-Oktober 2016 di Desa Mekarsari, Kecamatan Panimbang, Kabupaten Pandeglang, Banten. Bahan yang digunakan adalah benih kedelai varietas Gema, Urea, SP-36, NPK Phonska, pupuk hayati Agrimeth, pupuk hayati Gliocompost. Alat yang digunakanadalah cangkul, timbangan, bambu, papan nama, arit, meteran, buku dan alat tulis.

Penelitian menggunakan Rancangan Acak Kelompok (RAK) faktortunggaldengan lima tarafperlakuan dan enam ulangan. Perlakuan terdiriatas $\mathrm{A}=$ Tanpa pemupukan (Kontrol), B = Pupuk rekomendasi (Urea 25 $\mathrm{kgha}^{-1}+\mathrm{SP}-36100 \mathrm{kgha}^{-1}+100 \mathrm{~kg} \mathrm{NPK}$ Phonska), C = Agrimeth 200 gha $^{-1}+$ pupuk rekomendasi, D =Agrimeth 200 $\mathrm{g} \mathrm{ha}^{-1}+$ Gliocompost $20 \mathrm{kgha}^{-1}+$ pupuk rekomendasi, E $=$ Gliocompost $20 \mathrm{kgha}^{-1}+$ pupuk rekomendasi.

Ukuran petak percobaan 20mx8m dengan 30 jumlah petak percobaan. Lahan percobaan tanpa diolah.Benih kedelai varietas Gema ditanam 2 biji per lubang dengan jarak tanam 40 x $20 \mathrm{~cm}^{2}$.Aplikasi pupuk hayati Agrimeth dan Gliocompost dilakukan sesuai dengan petunjuk penggunaan yang telah ditentukan oleh Balittanah dan Balithi. Petunjuk penggunaan Agrimeth adalah benih kedelai dibasahi sampai cukup basah, ditiriskan dan dicampur rata dengan Agrimeth (200 gha $^{-1}$ ), benih yang telah dicampur Agrimeth segera ditanam dan sisanya dibenamkan di lubang tanam.Gliocompost diberikan sebagai penutup lubang tanam pada saat tanam kedelai dengan dosis $20 \mathrm{kgha}^{-1}$. Pemupukan anorganik Urea, SP-36 dan NPK Phonska dengan dosis Urea $25 \mathrm{kgha}^{-1}+100 \mathrm{kgha}^{-1}$ SP-36 + $100 \mathrm{kgha}^{-1}$ NPK Phonska. Waktu pemupukan yaitu seluruh dosis Urea, Phonska dan SP-36 diberikan pada tanaman kedelai pada umur 14 hari. Cara pemupukan yaitu secara tugal sepanjang barisan, sekitar $5 \mathrm{~cm}$ di samping barisan tanaman. Penyiangan dilakukan pada umur 30 dan 60 HST. Panen dilakukan pada umur 72-75 hari sesuai deskripsi varietas Gema (Balitkabi, 2013).

Parameter yang diamatiadalahtinggi tanaman $(\mathrm{cm})$, jumlah daun (lembar), panjang akar (cm), jumlah bintil akar, jumlahbunga, jumlah polong isi, hasil biji per hektar (tha $\left.{ }^{1}\right)$.Pengamatan tinggi tanaman dilakukan pada 10 tanaman contoh per petak perlakuan pada umur 15, 30, 42, 63 HSTdansaatpanen. Jumlah daun diukur pada umur 15, 30 dan 42 HST. Pengamatan, panjang akar, bintil akardanjumlahbunga dilakukan pada umur 42 HST dengan mengambil 10 tanaman per petak perlakuan. Penghitungan jumlah polong pada saat panen, dilakukan dengan mengambil 25 rumpun tanaman dari masing-masing petak perlakuan. Hasil biji kedelai diukur pada saat panen dengan melakukan ubinan berukuran 4 x 5 m pada setiap petak perlakuan. Hasil ubinan dari masing-masing perlakuan dikonversikan ke jumlah satuan yang sama yaitu hektar. Data hasil pengamatan dianalisis dengan menggunakan Analysis of Varians (ANOVA). Data yang berbeda nyata diuji lanjut menggunakan uji Duncan Multiple Range Test (DMRT)padatarafnyata $(\alpha) 0.5 \%$.

\section{HASIL DAN PEMBAHASAN}

Tinggi tanaman terbaik ditemukan pada perlakuan D. Agrimeth 200 gram/ha + Gliocompsot $20 \mathrm{kgha}^{-1}+$ pupuk rekomendasi (Gambar1). Kondisi menunjukkan bahwa dosispupuk hayati Agrimeth dan Gliocompost memberikanpengaruhpadapertumbuhan tinggi tanaman selama pemeliharaan. Padaperlakuan D, tinggi tanaman kedelai mengalami pertumbuhan sampai umur 63 HST sedangkan perlakuan $\mathrm{A}, \mathrm{B}, \mathrm{C}$ dan $\mathrm{E}$ pertumbuhan tanaman tidak mengalami peningkatan mulai umur 42 HST.

Jumlah daun terbaik ditemukan pada perlakuan pemberian Agrimeth $200 \mathrm{~g} \mathrm{ha}^{-1}+$ Gliocompost $20 \mathrm{~kg} \mathrm{ha}^{-1}+$ pupuk eksisting (Gambar 2). Jumlah daun tanaman 
bertambah pada umur 15 HST hingga 42 HST untuk semua perlakuan.

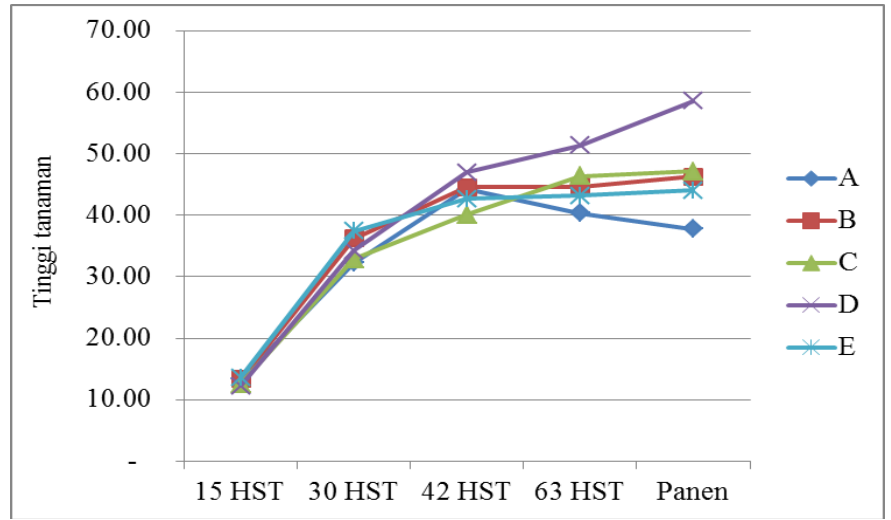

Gambar 1. Tinggi tanaman kedelai pada berbagai perlakuan pemupukan.

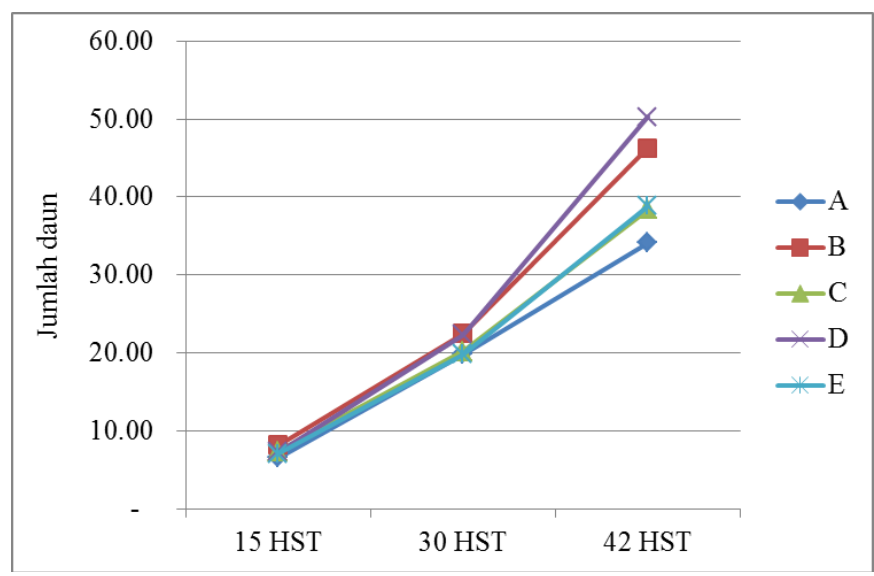

Gambar 2. Jumlah daun kedelai pada berbagai perlakuan pemupukan

Tabel 1 Pengaruh pemupukant erhadap tinggi tanaman, jumlah daun, panjang akar dan jumlah bintil akar dan jumlah bunga pada berbagai perlakuan

\begin{tabular}{cccccc} 
Perlakuan & $\begin{array}{c}\text { Tinggi tanaman saat } \\
\text { panen }(\mathrm{cm})\end{array}$ & $\begin{array}{c}\text { Jumlah daun } \\
\text { umur 42 }\end{array}$ & $\begin{array}{c}\text { Panjang akar umur 42 } \\
\text { HST }(\mathrm{cm})\end{array}$ & $\begin{array}{c}\text { Jumlah bintil akar } \\
\text { umur 42 HST }\end{array}$ & $\begin{array}{c}\text { Jumlah bunga } \\
\text { umur 42 HST }\end{array}$ \\
\hline A & $37.73 \mathrm{c}$ & $34.13 \mathrm{c}$ & $10.49 \mathrm{a}$ & $1.80 \mathrm{~b}$ & $37.50 \mathrm{~b}$ \\
$\mathrm{~B}$ & $46.25 \mathrm{~b}$ & $46.27 \mathrm{ab}$ & $10.52 \mathrm{a}$ & $2.60 \mathrm{~b}$ & $11.80 \mathrm{c}$ \\
$\mathrm{C}$ & $47.13 \mathrm{~b}$ & $38.40 \mathrm{bc}$ & $11.99 \mathrm{a}$ & $1.40 \mathrm{~b}$ & $8.07 \mathrm{c}$ \\
D & $58.57 \mathrm{a}$ & $50.27 \mathrm{a}$ & $13.11 \mathrm{a}$ & $7.10 \mathrm{a}$ & $42.53 \mathrm{a}$ \\
E & $44.05 \mathrm{~b}$ & $38.87 \mathrm{bc}$ & $12.39 \mathrm{a}$ & $2.50 \mathrm{~b}$ & $12.13 \mathrm{c}$ \\
\hline
\end{tabular}

Keterangan : Angka yang diikuti huruf yang sama pada kolom yang sama tidak berbeda nyataberdasarkan DMRT pada $\alpha=5 \%$

Tabel 2 Jumlah polong isi dan hasil biji kedelai pada berbagai perlakuan

\begin{tabular}{|c|c|c|}
\hline Perlakuan & Jumlah polong isi & Hasil biji kedelai $\left(\mathrm{t} \mathrm{ha}^{-1}\right)$ \\
\hline A & $33.17 \mathrm{~d}$ & $0.63 \mathrm{~d}$ \\
\hline B & $37.50 \mathrm{c}$ & $0.88 \mathrm{c}$ \\
\hline $\mathrm{C}$ & $39.67 \mathrm{bc}$ & $1.52 b$ \\
\hline $\mathrm{D}$ & $50.17 \mathrm{a}$ & $2.01 \mathrm{a}$ \\
\hline
\end{tabular}


E

$40.50 \mathrm{~b}$

$1.66 \mathrm{~b}$

Keterangan: Angka yang diikuti huruf yang sama pada kolom yang sama tidak berbedanyataberdasarkan DMRT pada $\alpha=5 \%$

Efektivitas pupuk hayati Agrimeth dan Gliocompost pada penelitian nampak pada pertumbuhan bintil akar yang lebih baik, yang menyebabkan kemampuan akar untuk menyerap air dan mengikat unsur hara $\mathrm{N}, \mathrm{P}$ dan $\mathrm{K}$ melalui kaloid tanah meningkat untuk mendukung pertumbuhan dan perkembangan tanaman. Unsur $\mathrm{N}$ diperlukan tanaman kedelai sebagai starter pada awal pertumbuhan, terutama bila kondisi lahan seperti kekeringan, lahan terlalu basah, tanah terlalu padat tidak kondusif bagi pertumbuhan bintil akar tidak baik maka serapan $\mathrm{P}$ dan $\mathrm{K}$ rendah (Mashuri, 2010).Tanaman kedelai yang mempunyai bintil akar efektif akan mengandung cukup $\mathrm{N}$ tanah melalui fiksasi $\mathrm{N} 2$ dari atmosfer, ketersediaan hara meningkat, uptake unsur hara meningkat, takaran pupuk berkurang, efisiensi pemupukan meningkat serta tanaman akan tumbuh lebih baik (Soedarjo, 2013).Selanjutnya Saraswati (2000) melaporkan bahwa manfaat dari penggunaan pupuk hayati adalah menyediakan sumber hara bagi tanaman, menstimulir perakaran agar berkembang sempurna.Suhartatik dan Sismiyati (2000) melaporkan hasil penelitian bahwa mikroba yang terdapat di dalam pupuk hayati mampu melarutkan unsur hara dan menyerap unsur hara.

Pada perlakuan Agrimeth 200 gha $^{-1}+$ Gliocompsot $20 \mathrm{kgha}^{-1}+$ pupuk rekomendasi memberikan jumlah polong isi kedelai per tanaman lebih banyak dibanding perlakuan lainnya (Tabel 2). Pemberian pupuk hayati Agrimeth $200 \mathrm{gha}^{-1}+$ Gliocompost $20 \mathrm{kgha}^{-1}+$ pupuk rekomendasi mampu meningkatkan jumlah polong isi per tanaman. Jumlah polong isi merupakan salah satu karakter yang berperan penting terhadap hasil biji kedelai (Sumarsono dan Zuraida. 2006; Sutoro et al., 2008; Hakim, 2012).Pada penelitian ini, nampak efektivitas pemanfaatan Agrimeth $200 \mathrm{gha}^{-1}+$ Gliocompost $20 \mathrm{kgha}^{-1}+$ pupuk NPK pada hasil biji kedelai lebih tinggi dibanding penggunaan pupuk hayati Agrimeth dan Gliocompost secara terpisah maupun dengan pemberian pupuk rekomendasi dan tanpa pemupukan (Tabel 2). Efektivitas pemanfaatan pupuk hayati Agrimeth dan Gliocompost terhadap hasil kedelai pada penelitian ini sama dengan hasil penelitian penggunaan produk pupuk hayati lainnya. Muzaiyanah et al.,(2015) melaporkan penelitian penggunaan pupuk hayati Santap NM1 dan Santap NM2 pada budidaya kedelai mampu meningkatkan jumlah polong isi per tanaman dan hasil kedelai. Sucahyono dan Harsono (2015) melaporkan hasil penelitianpenggunaan pupuk hayati Probio pada budidaya kedelai mampu meningkatkan hasil kedelai. Selanjutnya penggunaan pupuk hayati dapat meningkatkan hasil kedelai rata-rata 0,5 tha $^{-1}$ (Saraswati, 2013; PurwarnidanPratiwi (2015).

\section{KESIMPULAN}

Pemberian kombinasi pupuk hayati Agrimeth 200 gha $^{-1}+$ Gliocompost $20 \mathrm{kgha}^{-1}+$ pupuk rekomendasi pada budidaya kedelai di lahan sawah di Pandeglang, Banten mampu memberikan pertumbuhan dan hasil kedelai lebih baiksebesar $2.01 \mathrm{t} \mathrm{ha}^{-1}$.

\section{DAFTAR PUSTAKA}

Balai Penelitian Tanaman Hias. 2015. Pupuk Hayati Gliocompost. BalaiPenelitianTanamanHias, Bogor.

Balai Penelitian Tanah. 2015. Pupuk Hayati Agrimeth. BalaiPenelitian Tanah, Bogor.

BalaiPenelitianTanaman Aneka KacangdanUmbi. 2013. Deskripsi kedelai Varietas Gema. Balai Penelitian Tanaman Aneka Kacang dan Umbi, Malang. 25 hal.

Hakim, L. 2012. Komponen hasil dan karakter morfologi penentu hasil kedelai. Jurnal Penelitian Pertanian Tanaman Pangan.31(3):175-179.

Harsono, A.Subandi, dan Suryantini. 2012. Formulasi pupuk hayati dan organik untuk meningkatkan produktivitas aneka kacang 20\%, ubi $40 \%$ menghemat pupuk kimia 50\%. Laporan Hasil Penelitian Tahun 2010. Balitkabi. 53 halaman.

Harsono, A., Subandi, Hamastini, D.Santosa, dan A.Sariya. 2013. Kajian keefektifan pupuk hayati pada kedelai di lahan kering masam. Laporan Kerjasama Badan Penelitian dan Pengembangan Pertanian dengan Komite Inovasi Nasional. 22 halaman.

Manshuri, A. G. 2010. Pemupukan N, P dan K pada kedelai sesuai kebutuhan tanaman dan daya dukung lahan. J Penelitian Pertanian Tanaman pangan. 29(3):171179.

Muzaiyanah, S., A.Kristiono; Subandi. 2015. Pengaruh pupuk organik kaya hara Santap NM1 dan Santap NM2 terhadap pertumbuhan dan hasil kedelai pada tanah vertisol. Buletin Palawija. 13(1):74-82.

Purwani, J dan E. Pratiwi. 2015. Pengaruh pupuk hayati terhadap pertumbuhan dan hasil kedelai pada ultisols Kabupaten Serang di rumah kaca.hal 155-162. DalamRahmianna, A.A., Sholihin, N. Nugrahaeni (Eds.). Prosiding PeranInovasiTeknologi Aneka KacangdanUmbidalamMendukung Program KedaulatanPangan. Malang 19 Mei 2015.

Saraswati, R. 2000. Perananpupuk hayati dalam peningkatan produktivitas pangan. hal 46-54. Dalam Suwarno, et $a l$. (Eds.). Prosiding Tonggak Kemajuan Teknologi Produksi Tanaman Pangan: Paket dan komponen Teknologi Produksi Padi.Bogor, 22-24 November 1999.

Saraswati, R. 2013. Potensi penggunaan pupuk mikroba secara terpadu pada kedelai. hal.375381.DalamSumarno, Suyamto, A. Widjono, Hermanto, H. Kasim (Eds.). Kedelai Teknik Produksi dan Pengembangan. Badan Penelitian dan Pengembangan Pertanian, Pusat Penelitian dan Pengembangan Tanaman Pangan, Malang. 
Sasli, I. 2013. Respon tanaman kedelai terhadap pupuk hayati mikoriza arbuskula hasil rekayasa spesifik gambut. Agrovigor. 6(1):73-80.

Soedarjo, M. 2013. Teknologi Rhizobium pada tanaman kedelai. hal.345-374.DalamSumarno, Suyamto, A. Widjono, Hermanto, H. Kasim (Eds.).Kedelai Teknik Produksi dan Pengembangan. Badan Penelitian dan Pengembangan Pertanian, Pusat Penelitian dan Pengembangan Tanaman Pangan, Malang.

Sucahyono, D. dan A. Harsono. 2015. Keefektifan pupuk hayati di lahan non masam. hal 142150.DalamRahmianna, A.A., Sholihin, N. Nugrahaeni (Eds.). Prosiding PeranInovasiTeknologi Aneka KacangdanUmbidalamMendukung Program KedaulatanPangan. Malang 19 Mei 2015.
Suhartatik, E dan R. Sismiyati. 2000. Pemanfaatan pupuk organik dan agent hayati pada padi sawah. DalamSuwarno, et al., (Eds.). ProsidingTonggak Kemajuan Teknologi Produksi Tanaman Pangan: Paket dan komponen Teknologi Produksi Padi. Bogor, 22-24 November 1999.

Sutoro, Dewi,N dan Setyowati, M. 2008. Hubungan sifat morfologis tanaman dengan hasil kedelai. JPenelitianPertanianTanamanPangan.127(3):1851190.

Sumarsono dan Zuraida. 2006. Hubungan korelatif dan kausatif antara komponen hasil dengan hasil biji kedelai.

JPenelitianPertanianTanamanPangan.25(1):38-43. 